Citation: Britton, T.C. Stewart, R.A. O'Halloran, K.R. (2013) Smart metering: enabler for rapid and effective post meter leakage identification and water loss management, Journal of Cleaner Production, Volume 54, Pages 166-176, ISSN 0959-6526, http://dx.doi.org/10.1016/j.jclepro.2013.05.018.

\title{
Smart metering: enabler for rapid and effective post meter leakage identification and water loss management
}

\begin{abstract}
Authors:
Tracy Britton

PhD Candidate, School of Engineering, Griffith University, Gold Coast Campus 4222, Australia, Email: tracy.britton@griffithuni.edu.au
\end{abstract}

\section{Rodney A. Stewart (corresponding author)}

Director, Centre for Infrastructure Engineering \& Management, Griffith University, Gold Coast Campus, 4222, Australia, E-mail: r.stewart@griffith.edu.au

\section{Kelvin O’Halloran}

Principal Coordinator - Scientific Services and Data Systems, Seqwater, Brisbane, Queensland, Australia, Email: kelvin.o'halloran@seqwater.com.au 


\begin{abstract}
Periods of urban water scarcity in cities places pressure on government agencies and water utilities to improve water distribution system efficiency through reducing the amount of water lost in the network as well as deploying a range of demand management techniques to conserve existing supply. Current estimations assume customer post meter leakage accounts for up to $10 \%$ of total water consumption, particularly in the residential sector. Households identified as having post meter leakage using a citywide installation of smart metering technology were subjected to a mix of basic and tailored information regarding water loss. The primary aim of the study was to test the effectiveness of communication interventions and the attributed water savings resulting from the repair of household leaks. The residential leakage communication strategy resulted in a reduction in minimum night flows by a very significant $89 \%$ over the duration of the study, while the control group receiving no communication increased consumption by $52 \%$. Moreover, questionnaire surveys were conducted to establish the significant factors, including leak type, demographics and household awareness, to name a few, that will influence the development of a fit-for-purpose post-meter leak rectification policy and program. The paper concludes with some key recommendations for future work to develop a predictive model for identifying, classifying and quantifying post meter loss as well as presents least cost planning implications of a leak rectification policy. The study confirmed that smart metering provides water utilities with a powerful tool to rapidly identify and action the significant volumes of post meter leakage occurring in our cities.
\end{abstract}

Keywords: post meter leakage, smart metering, customer response, water demand management, water loss management, water efficiency 


\section{Introduction}

\subsection{Water efficiency}

The advantage of reducing the amount of water used to achieve any service is important in Australia. The variability of rainfall coupled with population growth and strong economic development impels efficient supply and demand side water management (Beal et al., 2011; Willis et al., 2010; Makki et al., 2011). Water is conveyed by systems with capacity limitations, and as system efficiencies tend to decrease as capacity is strained, it is imperative to maximise any efficiency in times of high and low water demands (Brooks, 2006). In times of water resource scarcity it is appropriate to determine the degree of technical efficiency of the total water supply network (Garcia and Thomas, 2001; Carragher et al., 2012). The water utility has two options when presented with higher water demand: (1) increase water output and not repair network leaks; or (2) repair network leaks and maintain same volume of water output (Brooks, 2006; Garcia and Thomas, 2001). Improving the efficiency of the water system is almost always a lower cost option than constructing capital intensive water supply infrastructure.

The occurrence of network leaks as part of the production and distribution process is classified as an overall inefficiency of the water system (Garcia and Thomas, 2001; Covas and Ramos, 2010). Network leakage is usually monitored in district metered areas by measuring the Minimum Night Flow (MNF) at designated time intervals; a leak is suspected when the MNF exceeds a predetermined threshold (Hunaidi and Wang, 2006). This leakage is expensive in terms of time to locate and labour to repair. Much has been written about leakage from mains and service pipes however literature regarding water losses located within residential household boundaries is limited (Britton et al., 2008, 2009). Post-meter household leakage can occur in any number of different plumbing fixtures or piping within a residential property. The development of policies and programs for the reduction in post meter leakage has received a low priority by water utilities. This situational context has been largely due to their current metering system not being able to provide sufficiently detailed water use information for the effective implementation of such programs. Krozer et al., (2010) proposes that innovation may improve how the water supply chain is managed at lower costs; post-meter household leakage repair may be one such innovation for water managers to consider. Stewart et al., (2010) also indicate that one of the key benefits of smart metering is the ability to identify and action customer leakage. 


\subsection{Smart metering}

There is no single definition or consensus on what it means for a meter or metering system to be classified as 'advanced' or 'smart' regardless of utility (gas, water or electricity) (Brophy-Haney et al., 2009; Darby, 2010). Darby (2010) comments that the realities of smart metering are simple; a smart meter is a meter that stores and transmits measurements at frequent intervals. They can also play an important role in the collection of a registry of end use water consumption data (Willis et al., 2011a, 2011b; Froehlich et al., 2011) including the detection of leaks in existing dwellings (Britton et al., 2008; Stewart et al., 2010). Advanced water metering and communications technologies enables data transfer of end-use water consumption data; analysis of this high resolution data pinpoints unusual patterns caused by water wastage (Ferreira et al., 2007).The importance of managing customer data at this high level should not be underestimated (Even et al., 2010). This information assists in operational management (e.g. Beal and Stewart, 2013) as it highlights households with excessive water consumption indicating inefficient use and option for leak investigation (Ferreira et al., 2007; Stewart et al., 2010).

\subsection{Residential water end use studies}

Residential consumption of water consists of a number of micro components (Kowalski and Marshallsay, 2005). Measurement of these components; toilets, taps, showers etc. referred to as end uses, provide information on the way water is used in and around the home. There are two approaches to monitoring residential water end use (1) typical end use and (2) advanced water end use measurement depending upon the type of water meter and data capture technology (Beal and Stewart, 2011). Typical end use studies measure water use via a smart meter using high resolution data in combination with household audits to check appliance stock and self-compiled water use diaries by residents (Beal and Stewart, 2011; Willis et al., 2009). Currently utilised smart metering technology can measure water consumption at resolutions of $0.014 \mathrm{~L}$ (Willis et al., 2009) to $5 \mathrm{~L}$ (Britton et al., 2009) and at time intervals of 1 to 5 s (Giurco et al., 2010), 10 s (Willis et al., 2009; Heinrich, 2007) and $1 \mathrm{~h}$ (Britton et al., 2009). The meter and logger determine the richness of data (Willis et al., 2009) and the level of investment correlates to the complexity of technology and behaviour change potential (Giurco et al., 2010). Software packages such as Trace Wizard ${ }^{\circledR}$ study the consistency in the flow trace patterns of water use; leaks are identified and quantified from their continuous trace data (Mayer et al., 1999). The smart metering system in Hervey Bay is suited to leak detection, peak demand 
identification and time of use tariff investigation due to the lower resolution of logging at hourly intervals (Stewart et al., 2010; Cole et al., 2012; Cole and Stewart, 2012).

\subsection{Post meter leakage studies}

Post meter leakage has a major effect on household water consumption (Arthuraliya et al., 2012; Water Corporation, 2010; Heinrich, 2008). Yarra Valley Water’s future water study (Arthuraliya et al., 2012) which recalibrates the prior Melbourne residential end use study (Roberts, 2004) shows that post meter leakage accounts for $2 \%(n=337)$ of total water usage. Interestingly in this study, Trace Wizard (i.e. end use categorisation software) identified drips as leakage; 90,000 leakage events lasting less than $10 \mathrm{~s}$ were drips at the end of closing taps and toilets cisterns (Arthuraliya et al., 2012). Each home experienced some form of minor leakage during the project. The authors comment here that these leakage events should possibly be termed background leakage (Lambert, 1994) as this is not a behavioural issue of households but more to do with the operating mechanisms of taps and toilets. Water Corporation's (2010) Perth Residential Water Use Study (PRWUS) conducted in 2008/2009 which updated a prior Perth Domestic Water Use Study (Loh and Coglan, 2003) found $17 \%$ ( $n=$ 1,868) of homes had leaks with an average flow rate from $1.8 \mathrm{~L} / \mathrm{h}$ to $66 \mathrm{~L} / \mathrm{h}$. The PRWUS proposed that the reduction of post meter leakage by $25 \%$ would reduce residential water consumption by $1 \%$ thus saving 1.7 GL/y (Water Corporation, 2010). The Auckland (New Zealand) Water Use Study (Heinrich, 2008) found that $13 \%(n=51)$ of total water usage was attributed to leaks, with one household losing 2,300 L/h. The Auckland findings were in line with previous end use studies (Roberts, 2004; Mayer et al., 1999, 2004) in that a small number of homes were responsible of the majority of leaks.

\subsection{Role of water conservation and management strategies}

User/customer information is often used to encourage conservation; many studies in the energy sector encourage households to reduce their energy use on a voluntary basis (Abrahamse et al., 2007). For example, the Home Water Wise Service (HWWS) launched in April 2006 was an initiative to assist in drought management and achieve long term water savings for the South East Queensland, Australia. For this program, an investment of US\$20 for each customer engaged the services of a licensed plumber to install a water saving showerhead, efficient aerators on bathroom and kitchen taps and fix 
up to three leaking taps. Approximately 188,888 household audits completed the HWWS and achieved savings of 4,288 ML of water or around 20.9 kL per household per annum (Coates and Bullock, 2008; Turner et al., 2005). In California, Gleick et al. (2003) estimated that indoor residential water use could be reduced by as much as $40 \%$ by replacing inefficient toilets, washing machines, showerheads, dishwashers and by reducing the level of household leaks; which accounted for $12 \%$ of indoor residential water use in 2000. The report goes onto state that leak rates could be reduced by $80 \%$, inferring that $50 \%$ of leaks can be repaired for less than US\$100 and $80 \%$ for less than US\$200.

Mayer et al., (1999, 2004) suggest that leak reduction programs targeted at homes with highest suspected leakage rates would be most effective. A number of utilities in California have experimented with mailing letters and brochures to the highest $36 \%$ of residential water users and the highest $10 \%$ received a follow up phone call (Gleick et al., 2003). A recent investigation into water use in Oklahoma (USA) revealed that repairing leaks was the principal conservation decision adopted by residents (Padgett, 2011).

Tailored information offers an even more effective way to encourage behavioural changes (Abrahamse et al., 2007; Desmedt et al., 2009; De Vries et al., 2008). Tailoring originated in health psychology; involving a series of interventions designed to change unhealthy habits, using data from or about a specific individual to determine the appropriate information to derive a related outcome (Abrahamse et al., 2007). De Vries et al. (2008) hypothesized that tailored information would be more effective than generic information in promoting compliance with recommendations.

Smart metering and associated resource consumption visual display technologies enable utility customers to access their consumption and compare with others in the community. Willis et al. (2010) introduced an alarming shower monitor device in residential households and demonstrated a reduction in shower use consumption in the short term however a subsequent study by this research group indicated a rebound in consumption over the long term (Stewart et al., 2011). These studies indicate that information feedback is effective in managing water demand but must be reinforced over time in order to instil water conservation habits (Fielding et al., 2012). In particular, identifying and communicating leakage to customers is something that must be conducted on an ongoing basis (i.e. weekly reports) as new leaks originate in a household or business premise each day. 
Prior research by the authors has provided evidence that the characteristics of post-meter flow events may be a reliable indicator of the type of leak e.g. toilet, service pipe, etc. (Britton et al., 2008). However, leak events are dynamic in nature and the decision to rectify them will be dependent on a number of monetary and non-monetary factors. Moreover, the decision will also be dependent on value judgements from the perspective of the water user, utility and government agencies. Nonetheless, one key decision driver to repair specific categories of leaks can be based on their cost and quantifiable water savings.

This paper firstly outlines the objectives and methodology followed for the study. Results are then presented including water savings attributable to leak alert communications and householder key concerns for and actions taken to address water loss. The paper finishes with study conclusions and an outline of the future directions of our ongoing research.

\subsection{Research objectives}

In brief, the study examined the extent to which the staged dissemination of both generic and tailored information on evident water leaks would result in leak repair and ultimately water savings. As detailed later, households where a leak was reported by the smart meters via a leak alert were subjected to a staged communication process. This involved increasingly detailed leak information letters being sent and meter reads after a reasonable period allowing householders to make repairs. Darby (2010) proposed that the challenge is to develop communications that can be used to select the most useful information for the customer combining advice and other pointers to enable effective action. The objective of the experimental design is to compare the actions of each group after each communication. The process used to determine the effect of the experiment is the recording of water consumption data pre and post communication and if households responded to the treatment. In summary, the study aimed to collect information that would provide insight on two primary research questions:

1. What are the water savings attributable to tailored communication interventions on household post meter leakage?

2. What are householder concerns for and actions taken to address informed water loss? 


\section{Research method}

\subsection{Study region}

The City of Hervey Bay is situated on the Queensland coast approximately $300 \mathrm{~km}$ north of Brisbane, Australia. The estimated residential population in June 2007 was 53,551 (ABS, 2006). Strong environmental legislation and regular droughts coupled with a growing population of 3-5 \% per annum (ABS, 2006) motivated Wide Bay Water Corporation (WBWC) to undertake aggressive water loss and demand management programs (Waldron et al., 2009). Table 1 illustrates WBWC’s key performance indicators in accordance with methodologies from the International Water Association Water Loss Task Force. During 2007, WBWC implemented an automated 'smart' meter reading (AMR) system. All 22,000 domestic water meters in the city were replaced with Elster V100 meters that have a FIREFLY $^{\circledR}$ data logger attached. The loggers record hourly volume (consumption) data, and transmit to a receiver on a hand-held computer or in a drive-by unit. Post meter leakage is identified during the meter reading process when a trickle alert flags continuous use in the previous $48 \mathrm{~h}$.

$<$ Insert Table 1 here $>$

\subsection{Sample}

A water meter reading cycle was conducted between March and May 2009, which covered all 22,000 residential households in Hervey Bay. From this reading cycle approximately $4 \%$ of residential properties were identified as having a leak according to the aforementioned leak alert process. Approximately 803 or $3.8 \%$ of households were retained for further assessment. WBWC use a local government business application holding information on land value and land size for the purpose of rates. The database contains contact addresses of the homeowner allowing for determination of owner occupied or rental properties. The 803 households were stratified according to suburb and land value. Of this group a sample of 372 households were randomly selected and notified of a potential leak. The 372 households were divided into two groups, named Group A $(n=332)$ and B $(n=40)$, with each group receiving a different communication intervention strategy over a three month period (Table 2). A control group $(n=100)$ was also selected and received no information during the course of the study. The research sample was specifically targeted at those residential dwellings that had a leak identified since the objective of the study was to determine the influence of leak event feedback to customers on 
reductions in leakage. This approach was required to achieve study objectives. Readers should note that households having large leaks may not necessarily be representative of the overall socio-demographics of the community examined. There is potentially a higher likelihood of a certain age of household (> 25 years old), resident profile (e.g. elderly couple), tenancy (e.g. renter) or even household income. Further investigation by the authors seeks to unpack the likely socio-demographic predictors of households with major leakage in order that targeted pre-emptive post meter leakage reduction strategies can be formulated.

\subsection{Communication interventions}

As detailed in Table 2 a series of interventions, feedback and questionnaire survey communications were conducted during the research process. The first communication to Group A involved a basic letter indicating that their household may have a leak and a fact sheet page featuring information on the capability of the meter reading system, leak alerts after continuous use and a step-by-step guide on how and where to check for leaks was mailed to all households in the sample.

$<$ Insert Table 2 here $>$

It should be noted that the first communication to Group A involved no household specific data analysis. However, the first communication to Group B involved extended analysis of household MNF water use to illustrate a leak was most likely present. Water meters were read four weeks after each communication allowing householder's time to digest information and decide the appropriate course of action. Other increasingly detailed communications (see Table 2) followed this approach in a similar manner. For the $3^{\text {rd }}$ and $2^{\text {nd }}$ communication for Group A and B, respectively, financial incentives (rebates) were offered to assist with the cost of leak repair. A rebate offered AUD\$100 towards plumbing repair; householders could either contact a recommended plumber who would deduct AUD\$100 from the bill or arrange for their own plumber and apply for a AUD\$100 rebate. Again, Group C (Control) did not receive any communication.

\subsection{Questionnaire survey}

The objective of the post-hoc evaluation survey was to understand the types of leaks occurring, residents' concerns for and actions taken to address water loss and household demographics. All 
survey recipients were informed that their responses would help better detect leakage, develop and enhance leak prediction models and devise effective policies to reduce this type of loss. Respondents were mailed a survey form and given a date by which to respond and enter a prize draw. There was also a web link provided to complete the survey online. The questionnaire structure solicited information from householders on the type of leak uncovered, their concerns and motivations when deciding to repair a leak, their perception on the quality of leak information provided, and their opinions on the degree and type of information that would influence other households in the future. This information helped to contextualise the empirically determined changes in MNF data pre- and post- intervention (i.e. leakage communication).

\section{Data analysis and results}

\subsection{Extracting leak data and typologies}

Firstly, water use data in CSV file format is exported to MS Excel and reviewed to confirm if a leak exists, then the leak typology (Britton et al., 2009) is established, followed by the determination of the leak flow rate and cumulative volume loss; culminating in a unique leak profile for each household in the study. The purpose of the leak profile is twofold; firstly to see the impact of each communication and secondly to understand the progressive nature and volume of water loss. A future intention, when enough typologies have been analysed, is to predict the causative agent of the leak and pass this information to the household to make leak rectification more efficient.

When identifying total leakage post meter, the leakage component must be separated from consumption. The MNF between 1am - 4am (i.e. industry recognised period of day where there is very low water use consumption) is converted to a graph, illustrating a pattern. Pattern recognition for identifying leakage characteristics can be based on frequency and volume in data organisation; that is, the category of leak in terms of constancy and the flow rate of the leak in terms of variability are both immediately apparent in graphed data (Britton et al., 2009). Figure 1a displays limited MNF activity and then a rapid rate of rise leak starting at $13 \mathrm{~L} / \mathrm{h}$ progressing to $450 \mathrm{~L} / \mathrm{h}$.

Night time irrigation is evident when studying water use profiles; a typical example is usage of >300 L/h between 1 am and 4 am repeatedly on alternate or every 3 to 4 nights. Figure 1b illustrates 
a household profile with a $20 \mathrm{~L} / \mathrm{h}$ constant leakage with legitimate consumption spikes of $>450 \mathrm{~L} / \mathrm{h}$ on several days matching suggested outdoor usage. For the purpose of this study, data has been normalised and does not include any major irrigation events. The continuous nature of the flow is assumed leakage and any spikes in use are considered elements of legitimate consumption (e.g. toilet flush or shower event of shift water). The average flow rate minus consumption is the average leak rate per hour (Britton et al., 2008, 2009). When a household is not experiencing a significant water leak the MNF is of random occurrence and does not follow a consistent pattern (Figure 1c).

$<$ Insert Figure 1a here $>$

$<$ Insert Figure 1b here $>$

$<$ Insert Figure 1c here $>$

\subsection{Meter accuracy and background leakage}

The minimum performance registration of the Elster V100 meter used in this study is $3 \mathrm{~L} / \mathrm{h}$. Water meters have measurement limitations and the ability to record consumption at low flow rates is difficult (Arregui et al., 2005). There is still limited understanding of meter accuracy when considering the starting or minimum registrations levels $\left(\mathrm{Q}_{\mathrm{s}}\right)$, therefore water with a flow rate that is below the $Q_{s}$ flow rate of the meter cannot be measured (Mukheibir et al., 2012). The authors acknowledge that there would be an element of background leakage which cannot be detected visually or measured by the meter in the study sample. However the three components of nonregistration of domestic water meters, namely, (1) non-registered water at low flow, (2) prevalence of low flow events and (3) the effect of water usage on $Q_{s}$ (Mukheibir et al., 2012) are applicable to all water meters not just those contained within this study. Quantifying the amount of water losses below meter registration $\left(\mathrm{Q}_{s}\right)$, particularly as a meter ages, is the subject of recent research interest (Mukheibir et al., 2012) and such studies should help to quantify this component of water loss.

\subsection{Effectiveness of post meter leakage communication interventions}

The effectiveness of communication interventions in terms of water savings are firstly reported and then findings from the questionnaire survey $(n=146)$ are discussed in order to contextualise them. Figures 2a, 3a and 4a display each study groups total MNF for the period 30 June 2008 to 30 June 
2009. All three groups show a distinctive rate of rise until the first intervention. Figures $2 b, 3 b$ and 4b display each study groups total consumption and leakage for the same period. The highest and lowest percentage of daily water consumption lost to post meter leakage for each study group was: Group A: $33 \%$ and $5 \%$; Group B: $72 \%$ and $7 \%$; and Control $71 \%$ and $21 \%$. Calculations indicate that Group A and B lost a respective 18.06 ML and 3.40 ML (Total = 21.46 ML) of water during a period of 275 days. The control group lost $12.42 \mathrm{ML}$ over a one year period.

$<$ Insert Figure 2a here $>$

$<$ Insert Figure 2b here $>$

Approximately 30 phone calls were received after the $1^{\text {st }}$ communication to Group A; requesting further information on the volume of water being lost. Conversations revealed the householders thought the loss amount could justify the expense of a plumbing professional. The majority of phone calls received after the $1^{\text {st }}$ communication to Group B were requests to check if the leak had stopped. As mentioned previously, financial incentives were included in the $3^{\text {rd }}$ and $2^{\text {nd }}$ communication for Group A and B, respectively. Fourteen households in Group A responded to the plumbing incentive offered in C3 (Figure 2). Despite Group B's steep decline in total MNF during C2 (Figure 3) only one household in Group B applied for a rebate.

$<$ Insert Figure 3a here $>$

$<$ Insert Figure 3b here $>$

$<$ Insert Figure 4a here $>$

$<$ Insert Figure 4b here $>$

\subsection{Leakage occurrence descriptive statistics}

Figure 5 illustrates the range of leak rates and frequency experienced by each group. The highest leak rate recorded was in Group A with one household losing $570 \mathrm{~L} / \mathrm{h}$. Group A involved four of the five largest leak rates which is not unexpected given the larger sample size. Group B highest loss was $180 \mathrm{~L} / \mathrm{h}$ and the Control Group was $480 \mathrm{~L} / \mathrm{h}$. The most common leak rate was $20 \mathrm{~L} / \mathrm{h}(n=$ 131) followed by $10 \mathrm{~L} / \mathrm{h}(n=100)$. Over $49 \%$ of leaks are $20 \mathrm{~L} / \mathrm{h}$ or less; this finding is consistent 
with leakage component analysis research conducted by Lambert (1994) which states that most leakage occurs from longer running moderate leaks. The rate and frequency of leakage contained in Group B is significant given the smaller sample size which may explain the saving results presented in Figure 5.

$<$ Insert Figure 5 here $>$

\subsection{Attributable water savings}

Table 3 details the hourly water loss prior to each intervention and reductions in loss attributed to each communication. Communication 1 to Group A (Table 3) resulted in the sample baseline hourly leakage rate reducing from 4,009 L/h to 2,644 L/h or $34.05 \%$. Communication interventions 2 and 3 resulted in further significant reductions. The entire series of communication interventions to Group A resulted in a significant $(p<0.001)$ total sample hourly leakage reduction of $87.68 \%$ (i.e. 4,009 L/h to $494 \mathrm{~L} / \mathrm{h})$.

$<$ Insert Table 3 here $>$

Group B (Table 3) total leakage reductions was even more pronounced with a $91.15 \%$ reduction achieved over the course of interventions (i.e. $1356 \mathrm{~L} / \mathrm{h}$ to $120 \mathrm{~L} / \mathrm{h}$ ). Combining the intervention samples, Group A and B final post-intervention hourly losses associated with leakage only accounted for $11 \%$ of the baseline value indicating a substantial reduction (89\%). This provides solid evidence that the large majority of households addressed household leaks. Group C (Table 3) experienced a decline in hourly leakage at meter read 3 (Figure 4) indicating that some households in the control may have located and repaired leaks. However, repairs are outweighed by leak rate of rises over study period resulting in an overall $52.2 \%$ increase in hourly leakage between the $1^{\text {st }}$ and $4^{\text {th }}$ meter read. The control group results reinforce discussions provided earlier that MNF reductions are due to reduced leakage from householder instigated repairs and not increases in legitimate consumption and also confirms that if leaks are left unattended they will rise substantially over a period of time. Presently, the majority of customers of water utilities having traditional water meters 
only seriously action water leaks after their quarterly or six-monthly water bill, when they are 'shocked' into action by its financial impact.

\subsection{Questionnaire survey findings}

Analysis of the questionnaire surveys $(n=146)$ received revealed that some households experienced no leak $(n=17)$, the majority of households confirmed one leak $(n=129)$ and the remaining households found two $(n=37)$ or three leaks $(n=9)$. Overall, 192 leaks and 15 different leak types were confirmed (Figure 6). $68.5 \%(n=100)$ of the respondents were owner occupiers and $31.5 \%(n=46)$ were property investors. Respondents stated the nominated repairer and the reason for that choice. Plumbers undertook repairs in $46 \%(n=56)$ of the households. 35 households indicated a natural default to call in a professional for the job. $16 \%$ of households either tried to fix the leak or could not locate the leak and opted to employ a Plumber. $29 \%(n=35)$ of households repaired the leak themselves stating cost, knowledge of how to and ease of repair as the major factors. Friends and family $(n=17)$ were responsible for repairing $14 \%$ of leaks; plumber, builders and tradespeople were known to or referred by other family members. Nearly $70 \%$ of the leaks were fixed for AUD\$200 or less. In total, only six leaks (5\%) had repair bills ranging from AUD\$1,501 to AUD\$4,000 mainly due to a leaking hot water system. These leaks were considerably more expensive as they involved concrete/wall excavation and replacement of internal copper piping as well as underground polyurethane pipes. The median cost per household repair ( $n$ $=121$ ) that responded to the questionnaire survey was AUD\$272.85.

\section{$<$ Insert Figure 6 here $>$}

When informed of the leak, $45 \%$ of respondents did not think the leak would be too costly to repair and $59 \%$ disagreed with the statement "I do not have time to repair". Only $26 \%$ of respondents were concerned with the cost of employing plumbing services and only $6 \%$ of respondents discounted the leak amount or considered that it was too insignificant to deal with. Possible damage and flooding was cited by $42 \%$ as the main concern when first receiving notification of a leak (Figure 7a). When the decision was made to repair, $73 \%$ of respondents said they felt obliged and $69 \%$ agreed that they would have to repair the leak in due course; this could possibly indicate that leaks were already known to many householders. Only $27 \%$ thought the water authority may 
enforce repair. $72 \%$ stated saving money as a main motivation and an encouraging $93 \%$ of respondents cite the main driver was preventing further unnecessary loss, (Figure $7 \mathrm{~b}$ ). $87 \%$ of respondents were happy to be informed and $84 \%$ would like more information of this kind in future. Interestingly, $62 \%$ would like the water authority to acknowledge that repairs had been undertaken and $75 \%$ said the information prompted affirmative action (Figure 7c).

$<$ Insert Figure 7 here $>$

When asked what would help other households decide to fix a leak (Figure 7d), assuming that each household received a basic letter, $92 \%$ of respondents stated that a detailed letter with the water loss amount in litres and dollar value of leak related water consumption as well as a graphical display would be the preferred form of information. $83 \%$ would like an indication of the leak type or where it was coming from and $74 \%$ wanted a prediction of cost and loss if no action was taken. An incentive for repair was favoured by $73 \%$ and only $35 \%$ were against a penalty notice. Having a timeframe within which to repair was not favoured by $16 \%$ of respondents and $66 \%$ recommended a follow-up call by the water utility.

\section{Study implications for urban water management}

Major urban centres across the globe will experience significant increases in demand due to population growth. Intelligent planning proffers that water professionals should examine the costs and benefits of all available water conservation options to see whether they demonstrate potential (Marsden Jacob, 2006). One of the ways a water utility can increase profitability; in this context we mean efficiencies across all areas of the business, is via cost minimisation (Altman, 2007). Labour and material cost involved in network repairs is higher than energy costs associated with increasing water production (Garcia and Thomas, 2001). The benefit of post meter leak detection also extends beyond the initial and physical water savings; a reduction in waste water has implications for both energy consumption and treatment costs (Arreguin-Cortes and Ochoa-Alejo, 1997).

The findings of this study are already aiding an improved understanding of the sources, frequencies and importance of night-time consumption (Lambert, 2010). Lambert (2010) proposed a standard terminology for the components of MNF (Figure 8). Extended investigation and survey analysis of 
the authors has provided insights into the Customer Night Leakage component of MNF; leakage on service connections and within customers' properties and the types of leaks occurring and range of loss (Britton et al., 2008, 2009). The questions concerning how much water is lost post meter in households and what measures can be used to target such losses are important for improving water management. This study shows that a water utility has an option of being proactive in dealing with post meter leakage through the roll-out of smart metering combined with the automated generation of leak event communications to customers. Study findings are of immense value to urban water managers attempting to reduce water demand or improve system efficiency. As demonstrated in this study, for those households having a significant leak in a particular city, which is typically 3-7 \% of all homes in any particular given time period, between one and two thirds of their total daily consumption is attributed to leaks (i.e. Group A: $33 \%(n=332)$; Group B: $72 \%(n=100)$; and Group C: $71 \%(n=40))$.

$<$ Insert Figure 8 here $>$

Interestingly the homeowners who made initial telephone calls and subsequently those who repaired leaks and informed us that they had done so did not complete the survey. However, they did provide information on the leak type and repair cost resulting in over one hundred additional confirmations

of leak type and cost. The reason for not partaking could be attributed to the fact that they felt they had already participated due to imparting some of the required information.

Future efficiency measures are likely to be more expensive and perhaps intrusive upon residential customers (WSAA, 2010). The key will be to identify the form of information which is most useful for decision making by household residents and the water utility (Giurco et al., 2010).

\section{Conclusion}

A staged communication strategy to householders $(n=372)$ regarding post meter leakage was found to reduce hourly water loss collectively by $89 \%$ over a period of three months. $70 \%$ of the leaks were repaired by householders for less than AUD\$200 and $50 \%$ for less than AUD\$100. 
Householders were happy to be informed of a leak and expressed a desire for future information of this nature. No particular barriers to repair were highlighted by survey respondents $(n=146)$. Environmental motivations for conserving water and reducing loss was higher than cost saving motivations.

\section{Future work}

\subsection{Developing predictive models}

The next stage of work involves developing a series of intelligent models that can provide predictions about post meter leakage characteristics. The first of which can determine total water loss due to post-meter leakage for a city or town and the second can predict the water loss and cost to households if no action is taken. The models will be a simplified representation about the phenomena of post meter leakage and optimised to provide adequate representation of the processes affecting this type of water loss (Ascough et al., 2008).

\subsection{Least cost planning}

During times of constrained supply and drought the above mentioned models will allow a water utility or government water agency to understand the nature and volume of loss. However the investment of time and budget on the part of the utility is also a significant consideration. This study involved a detailed record of time, resources and money dedicated to each communication intervention. This account coupled with anticipated reductions in production, pumping and treatment costs will allow the real cost of this water loss strategy to be determined using Least Cost Planning principles (Wu et al., 2012). It is envisaged that a leakage management strategy applying the approach outlined in this study will have a much lower unit cost $(\$ / \mathrm{kL})$ than many other water supply and demand management strategies available (Stewart, 2010).

\subsection{Post meter leakage policies}

The final research outcome will be to propose a policy framework for managing post meter leakage and the implementation of the associated enabling smart metering technologies. Such a policy framework and associated delivery guidelines need to be researched and formulated covering 
technical standards, communication protocols, incentives for water service providers through to end users, to name a few aspects. A policy theme of particular importance is the means of dissemination of information regarding post meter leakage and the degree of incentive for water utilities to identify customer leaks and potentially subsidise their repair. Normal practice in most water utilities having traditional metering technical and billing systems (i.e. manual data read every 3 to 6 months) is for the bulk of unattended post meter leakage to be paid by the customer unless it is a very significant service break and can be justified as invisible. As demonstrated in this study, smart metering technology enables water utilities to know, on a daily basis, those households with leaks, thus legal opinion may deem them responsible for informing customers and for informed customers to be potentially liable for making repairs in a reasonable time period. All such issues need to be adequately addressed through discussions with water utilities, government and customers, in order for such a policy to be effective.

\section{Acknowledgments}

The authors wish to acknowledge support from the Institute of Sustainable Futures. Particular thanks to Wide Bay Water Corporation for access to their facilities and assistance with data gathering, especially Bruce Yarrow and Kylie Borg.

\section{References}

Abrahamse, W., Steg, L., Vlek, C., Rothengatter, Y., 2007. The effect of tailored information, goal setting, and tailored feedback on household energy use, energy related behaviours and behavioural antecedents. J. Environ. Psychol. 27, 265-276.

Altman, D., 2007. Marginal cost water pricing: welfare effect and policy implication using minimum cost and benchmarking case studies from Australia and Asia. Doctoral Dissertation. University of Adelaide, South Australia.

Arregui, F.J., Cabrera, E., Cobacho, R., Garcia-Serra, J., 2005. Key factors affecting water meter accuracy. Proc. of IWA Leakage 2005 Conf. 12-14 Sep. 2005. Halifax, Canada. 
Arreguin-Cortes, F.I., Ochoa-Alejo, L.L., 1997. Evaluation of water losses in distribution networks. J. Water Resour. Plan. and Manag. 123(5), 284-291.

Arthuraliya, A., Roberts, P., Brown, A., 2012. Yarra Valley future water: residential water use study, Volume 2 - Summer 2012. Yarra Valley Water, Victoria, Australia.

Ascough, J.C., Maier, H.R., Ravalico, J.C., Strudley, M.W., 2008. Future research challenge for the incorporation of uncertainty in environmental and ecological decision making. Ecol. Modell. 219, 383-399.

Australian Bureau of Statistics (ABS), 2006. National regional profile: Hervey Bay, Queensland, Australia.

Beal, C., Stewart, R.A., 2011. South-east Queensland residential end use study: final report. Technical Report No. 47 for the Urban Water Security Alliance. Griffith University and Smart Water Research Centre, Gold Coast, Australia.

Beal, C., Stewart, R.A., Fielding, K., 2011. A novel mixed method smart metering approach to reconciling differences between perceived and actual residential end use water consumption. J. Clean. Prod. http://dx.doi.org/10.1016/j.jclepro.2011.09.007

Beal, C., Stewart, R.A., 2013. Identifying residential water end-uses underpinning peak day and peak hour demand. J. Water Resourc. Plan. and Manag. DOI: 10.1061/(ASCE)WR.19435452.0000357

Britton T., Cole, G., Stewart, R., Wiskar, D., 2008. Remote diagnosis of leakage in residential households. Water: J. Aust. Water Assoc. 35(6), 89-93.

Britton T., Stewart, R., Wiskar, D., 2009. Smart Metering as a tool for revealing the characteristics of household leakage during a typical reading cycle. Proc. of the OzWater Conf. 15-18 Mar. 2009. Melbourne, Victoria, Australia. 
Brophy-Haney, A., Jamasb, T., Pollitt, M.G., 2009. Smart metering and electricity demand: technology, economics and international experience. Electricity Policy Research Group Working Paper EPRG003. University of Cambridge, United Kingdom.

Brooks, D.B., 2006. An operational definition of water demand management. Int. J. Water Resourc. Dev. 22(4), 521 - 528.

Carragher, B.J., Stewart, R.A., Beal, C.D., 2012. Quantifying the influence of residential water appliance efficiency on average day diurnal demand patterns at an end use level: A precursor to optimise water service infrastructure planning. Resourc., Conserv. and Recycl. 62, 81-90.

Coates, B., Bullock, J., 2008. One by one but all at once: How to reduce excessive residential water demand one customer at a time... in a big hurry. Proc. of $3^{\text {rd }}$ Aust. Water Assoc. Natl. Water Effic. Conf. 30 Mar. - 2 Apr. 2008. Gold Coast City, Queensland, Australia.

Cole, G., O’Halloran, K., Stewart, R.A., 2012. Time-of-use tariffs: implications for water efficiency. Water Sci. Technol.: Water Supply. 12(1), 90-100.

Cole, G., Stewart, R.A., 2012. Smart meter enabled disaggregation of urban peak water demand: precursor to effective urban water planning. Urban Water J. DOI:10.1080/1573062X.2012.716446

Covas, D., Ramos, H., 2010. Case studies of leak detection and location in water pipe systems by inverse transient analysis. J. of Water Resourc. Plan. and Manag. 136(2), 248-257.

Darby, S., 2010. Smart metering: what potential for householder engagement? Build. Res. and Inf. 38(5), 442-457.

Desmedt, J., Vekemans, G., Maes, D., 2009. Ensuring effectiveness of information to influence household behaviour. J. Clean. Prod. 17, 455-462. 
De Vries, H., Kremers, S.P.J., Smeets, T., Brug, J., Eijmael.K., 2008. The effectiveness of tailored feedback and action plans in an intervention addressing multiple health behaviours. Am. J. Health Promot. 22 (6), 417-425.

Even, A., Shankaranarayanan, G., Berger, P.D., 2010. Evaluating a model for cost effective data quality management in a real-world CRM setting. Decis. Support Syst. 50 (1), 152-163.

Ferreira, V., Fleming, P., Stuart, G., Patel, P., Webber, P., Conway, S., 2007. Low hanging fruits or cost effective energy and water savings using intelligent metering and monitoring systems? Proc. of Eur. Counc. for Energy Effic. Econ. Panels of the 2007 eceee summer study. La Colle sur Loup, France.

Fielding, K.S., Spinks, A., Russell, S., McCrea, R., Stewart, R.A., Gardner, J., 2012. An experimental test of voluntary strategies to promote urban water demand management. J. Environ. Manage. 114, 343-351.

Froehlich, J., Larson, E., Saba, E., Campell, T., Atlas, L., Fogarty, J., Patel, S., 2011. A longitudinal study of pressure sensing to infer real-world water usage events in the home. Pervasive Comput. LNCS 6696, 50-69, DOI: 10.1007/978-3-642-21726-5_4

Garcia, S., Thomas, A., 2001. The structure of municipal water supply costs: application to a panel of French local communities. J. of Product. Anal. 16, 5-29.

Giurco, D.P., White, S.B., Stewart, R.A., 2010. Smart metering and water end-use data: conservation benefits and privacy risks. Water, 2, 461-467.

Gleick, P., Haaz, D., Henges-Jeck, C., Srinivason, V., Wolff, G., Kao Cushing, C., Mann, A., 2003. Potential for urban water conservation in California. Pacific Institute, Oakland, USA.

Heinrich, M., 2007. Water end use and efficiency project (WEEP) - final report. BRANZ Study Report No. 159, Judgeford, New Zealand. 
Heinrich, M., 2008. Water use in Auckland households - Auckland water use study (AWUS) final report. BRANZ Project Report EC1356, Judgeford, New Zealand.

Hunaidi, O., Wang, A., 2006. A new system for locating leaks in urban water distribution pipes. Manag. Environ. Qual.: An Int. J. 17(4), 450-466.

Kowalski, M., Marshallsay, D., 2005. Using measured micro-component data to model the impact of water conservation strategies on the diurnal consumption profile. Water Sci. Technol.: Water Supply. 5(3-4), 145-150.

Krozer, Y., Hophmayer-Tokich, S., Van Meerendonk, H., Tijsma, S., Vos, E., 2010. Innovation in the water chain - experiences in the Netherlands. J. Clean. Prod. 18, 439-446.

Lambert, A., 1994. Accounting for losses: bursts and background estimates. Water Environ. J. 8(2), 205-214.

Lambert, A., 2010. Improving the understanding of components of residential night consumption using Gold Coast and end use study data. Report by ILMSS Ltd on behalf of Wide Bay Water Corporation, Queensland, Australia.

Loh, M., Coghlan, P., 2003. Domestic water use study in Perth, Western Australia 1998 to 2000. Water Corporation of Western Australia. Perth, Australia.

Makki, A.A., Stewart, R.A., Panuwatwanich, K., Beal, C., 2011. Revealing the determinants of shower water end use consumption: enabling better targeted urban water conservation strategies. J Clean. Prod. doi:10.1016/j.jclepro.2011.08.007

Marsden Jacob Associates, 2006. Securing Australia's urban water supply: opportunities and impediments. A discussion paper prepared for the Department of the Prime Minister and Cabinet. Canberra, Australia. 
Mayer, P.W., DeOreo, W.B., Optiz, E.M., Kiefer, J.C., Davis, W.Y., Dziegielewski, B., Nelson, J.O., 1999. Residential end uses of water. Prepared for the AWWA Research Foundation USA. http://www.waterrf.org/PublicReportLibrary/RFR90781_1999_241A.pdf [date last accessed: 5 May 2013].

Mayer, P.W., DeOreo, W.B., Towler, E., Martien, L., Lewis, D.M., 2004. Tampa water department residential water conservation study: the impacts of high efficiency plumbing fixture retrofits in single family homes. Aquacraft Inc., Tampa, USA.

http://www.aquacraft.com/sites/default/files/pub/Mayer-(2004)-Tampa-Water-DepartmentResidential-Water-Conservation-Study.pdf [date last accessed: 5 May 2013].

Mukheibir, P., Stewart, R., Giurco, D., O’Halloran, K., 2012. Understanding non-registration in domestic water meters: implication for meter replacement strategies. Water: J. Aust. Water Assoc. 39(8), 95-100.

Padgett, M., 2011. Drivers of water use and conservation adaption by residential users in Oklahoma: motivation, attitudes and perceptions. Masters Dissertation. Oklahoma State University, USA.

Roberts, P., 2004. Yarra Valley residential end use measurement study. Yarra Valley Water Technical Report, Victoria, Australia.

Stewart, R.A., Willis, R., Giurco, D.P., Panuwatwanich, K., Capati, G., 2010. Web based knowledge management system: linking smart metering to the future of urban water planning. Aust. Plan. 47, 66-74.

Stewart, R.A., 2010. Verifying the end use potable water savings from contemporary residential water supply schemes. National Water Commission, Waterline Series Report No. 61. Canberra, Australia. ISBN: 978-1-921853-38-8 www.nwc.gov.au/_data/assets/pdf_file/0016/18007/61Verifying_potable_water_savings.pdf [date last accessed: 5 May 2013]. 
Stewart, R.A., Willis, R.M., Panuwatwanich, K., Sahin, O., 2011. Showering behavioural response to alarming visual display monitors: longitudinal mixed method study. Behav. Inf. Technol. doi:10.1080/0144929X.2011.577195

Turner, A., White, S., Bickford, G., 2005. The Canberra least cost planning study. Water Sci. Technol.: Water Supply. 5, 257 -263.

Water Services Association of Australia (WSAA), 2010. Implications of population growth in Australia on urban water resources. Occasional Paper No. 25. https://www.wsaa.asn.au/WSAAPublications/Occasional\%20Papers/Implications\%20of\%20populat ion\%20growth\%20in\%20Australia\%20on\%20urban\%20water\%20resources.pdf [date last accessed: 5 May 2013].

Waldron, T.J., Wiskar, D., Britton, T, Cole. G., 2009. Managing water loss and consumer use with pressure management. Proc. of $5^{\text {th }}$ IWA Water Loss Conf. 26-30 April 2009. Cape Town, South Africa.

Water Corporation, 2010. Perth residential water use study 2008/2009. Water Corporation Technical Report, Perth, Western Australia.

Wide Bay Water Corporation (WBWC), 2008. System loss management plan 2007 - 2008. Report to the Queensland Department of Natural Resources. Queensland, Australia.

Willis, R.M., Stewart, R.A., Panuwatwanich, K., Capati, B., Giurco, D., 2009. Gold Coast domestic water end use study. Water: J. of Aust. Water Assoc. 36(6), 79-85.

Willis, R.M., Stewart, R.A., Panuwatwanich, K., Jones, S., Kyriakides A., 2010. Alarming visual display monitors affecting shower end use water and energy conservation in Australian residential households. Resourc., Conserv. and Recycl. 54(12), 1117-1127. 
Willis, R.M., Stewart, R.A., Giurco, D.P., Talebpour, M.R., Mousavinejad, A., 2011a. End use water consumption in households: impact of socio-demographic factors and efficient devices. J. Clean. Prod. http://dx.doi.org/10.1016/j.jclepro.2011.08.006

Willis, R.M., Stewart, R.A., Williams, P., Hacker, C., Emmonds, S., Capati, G., 2011b. Residential potable and recycled water end uses in a dual reticulated supply system. Desalination. 272(1-3), 201-211.

Wu, L. Jiang, Q. Yang, X.M., 2012. Carbon footprint incorporation into least-cost planning of ecocity schemes: practices in coastal China. Procedia Environ. Sci. 13, 582-589. 


\section{List of Table Titles:}

Table 1. Hervey Bay Network System Performance 2007 - 2008 (WBWC, 2008)

Table 2. Communication interventions

Table 3. MNF values pre- and post- communication interventions 


\section{List of Figure Titles:}

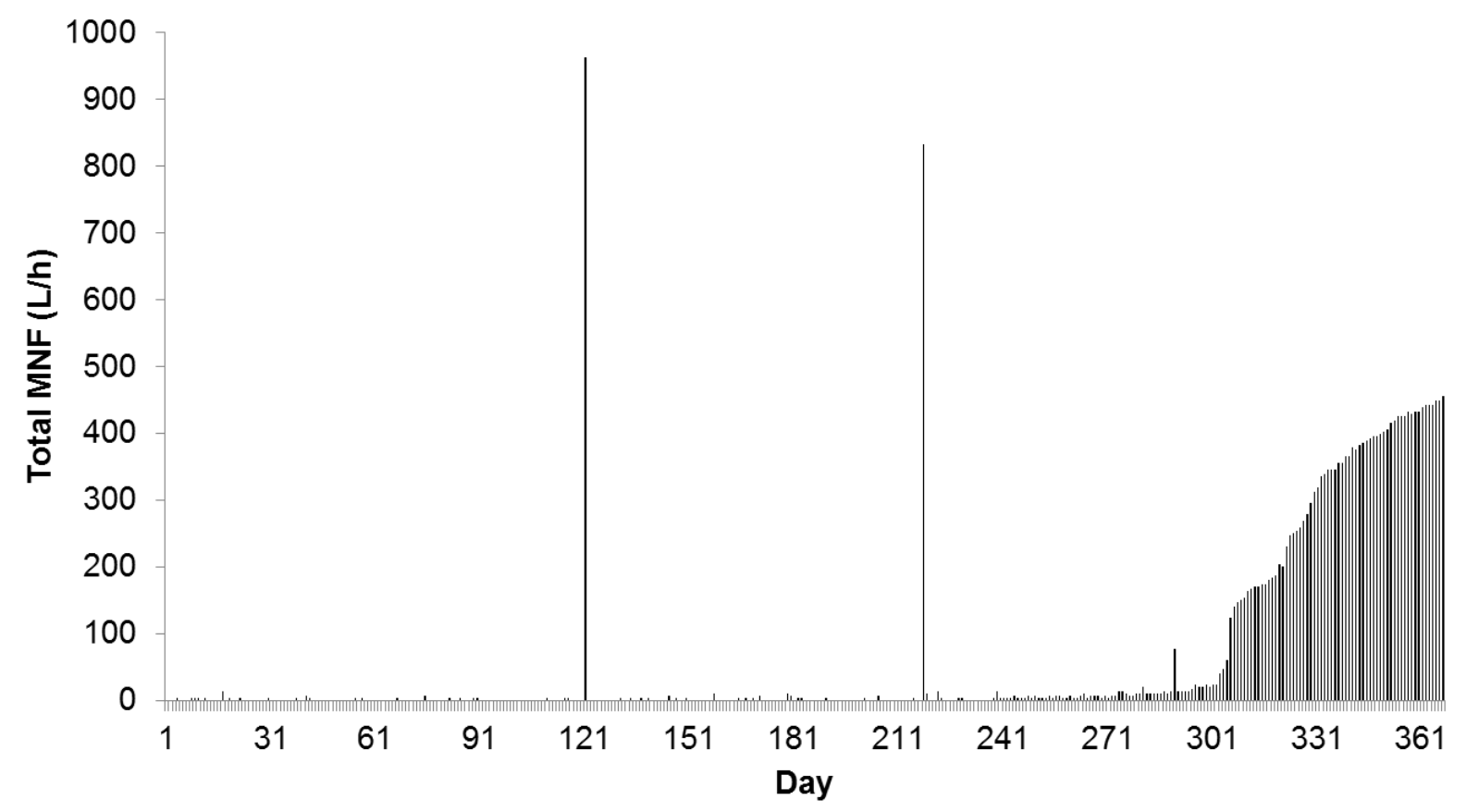

(a) Example of rapid rate of rise leak

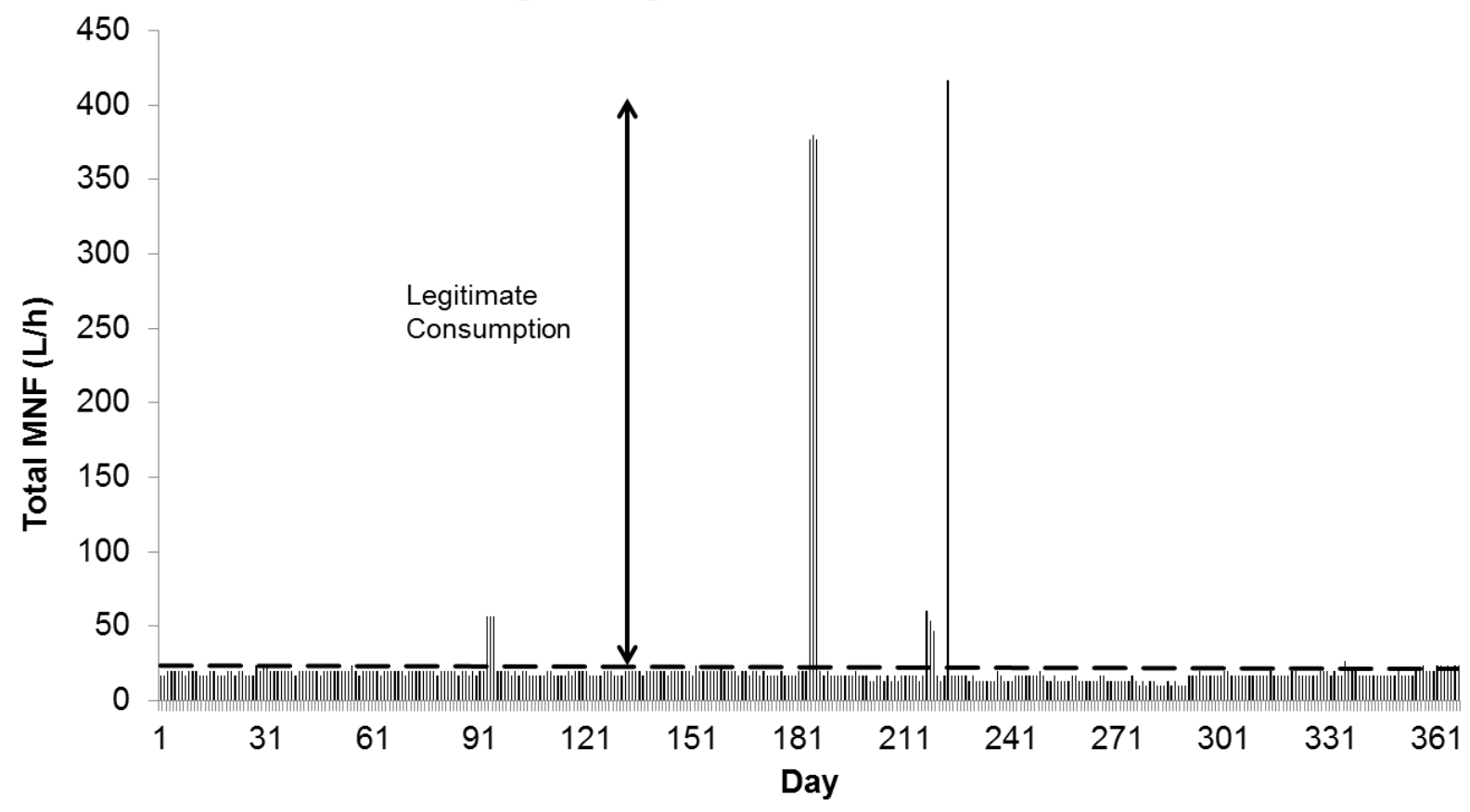

(b) Example of constant leak 


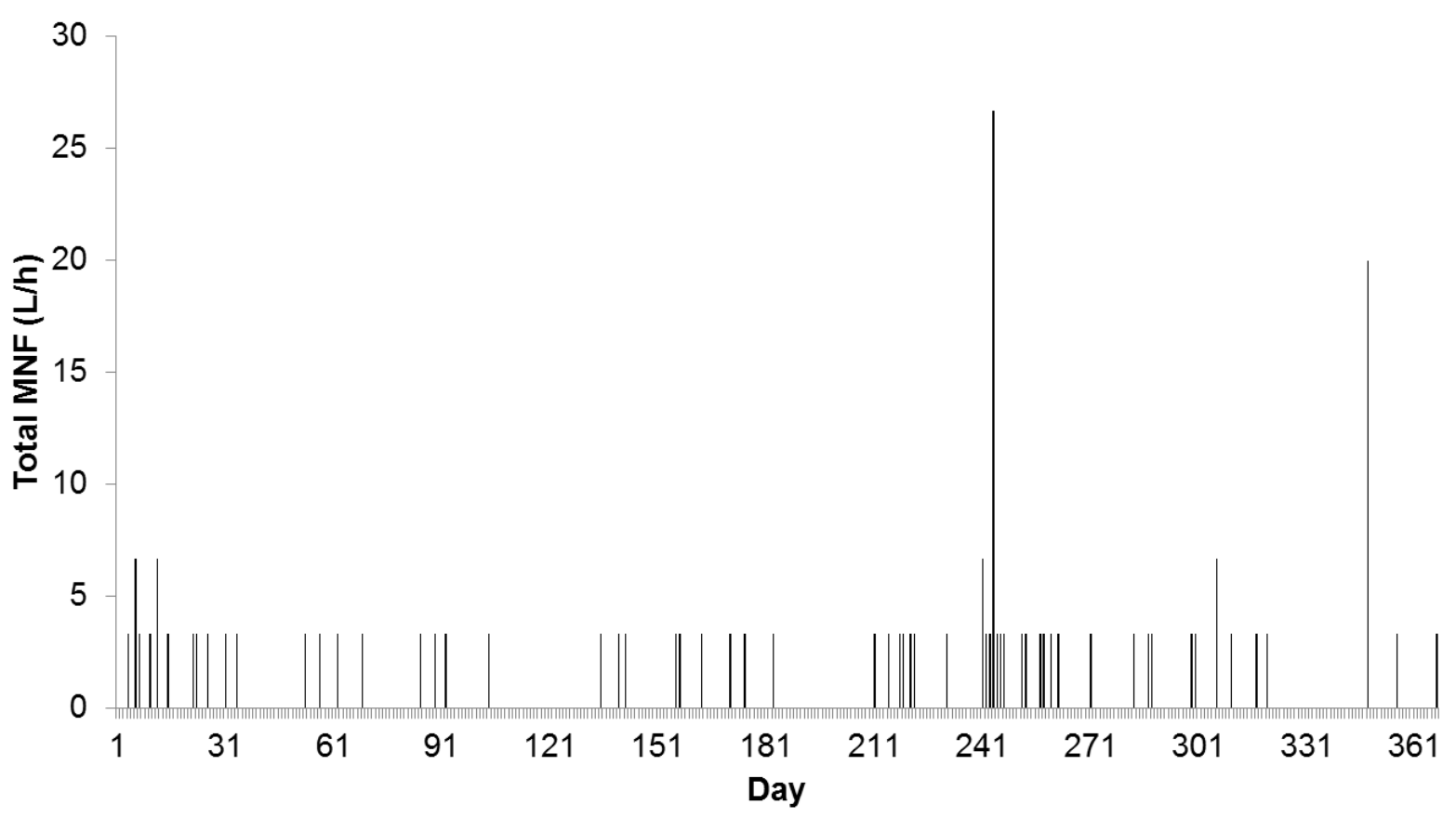

(c) Example of legitimate night water use

Figure 1. Leak occurrence and type examples

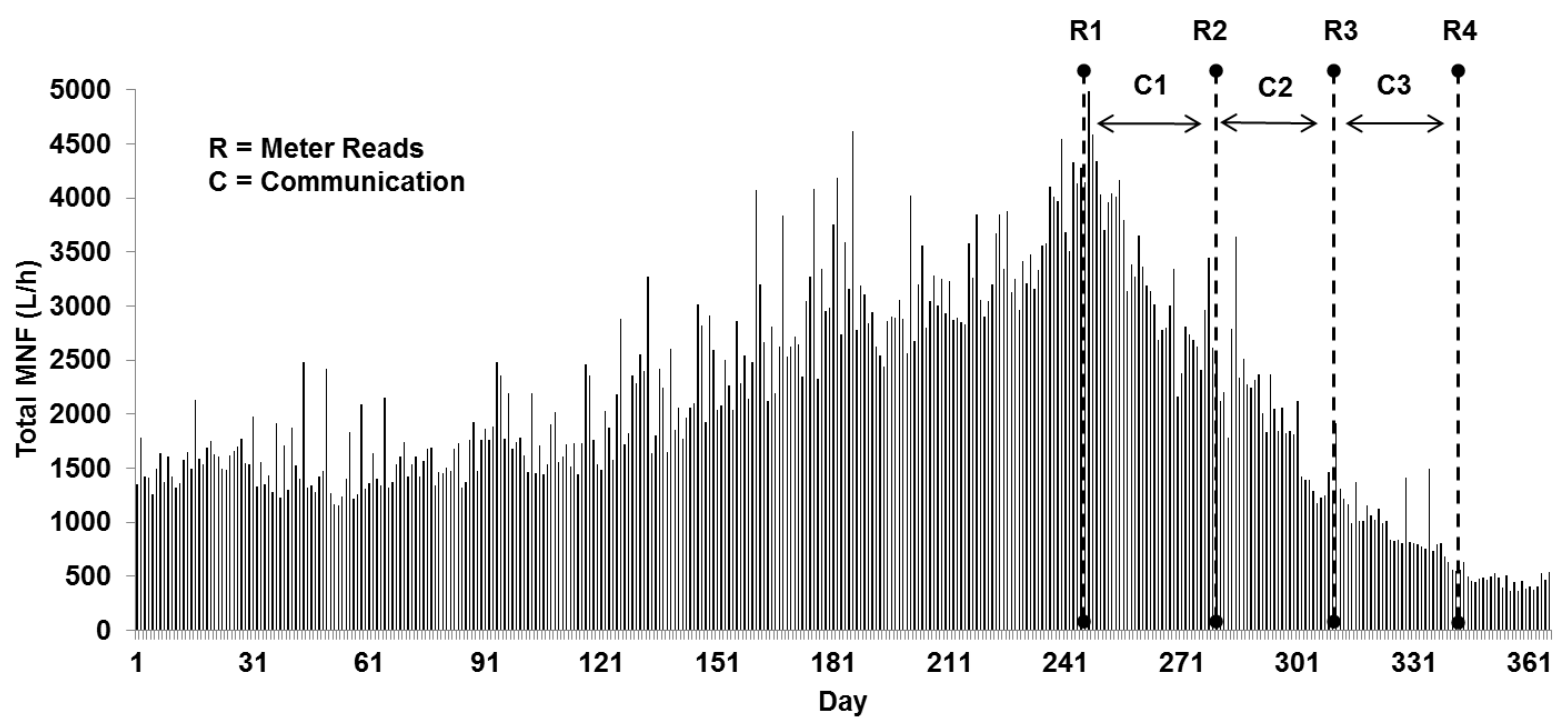

(a) Change in MNF over study period (pre- and post- intervention) 


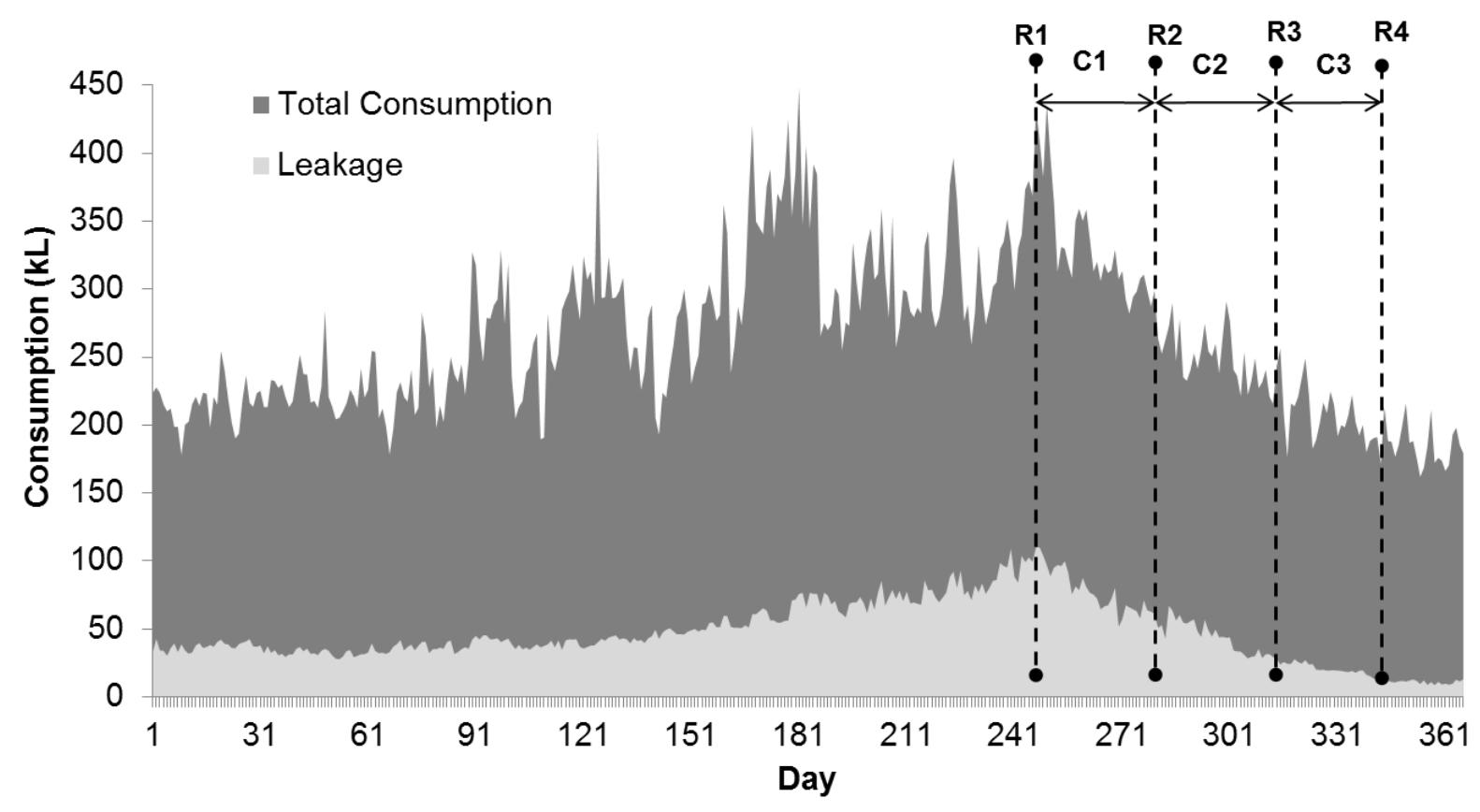

(b) Total and leakage consumption over study period (pre- and post- intervention)

Figure 2. Communication interventions affecting MNF for Group A

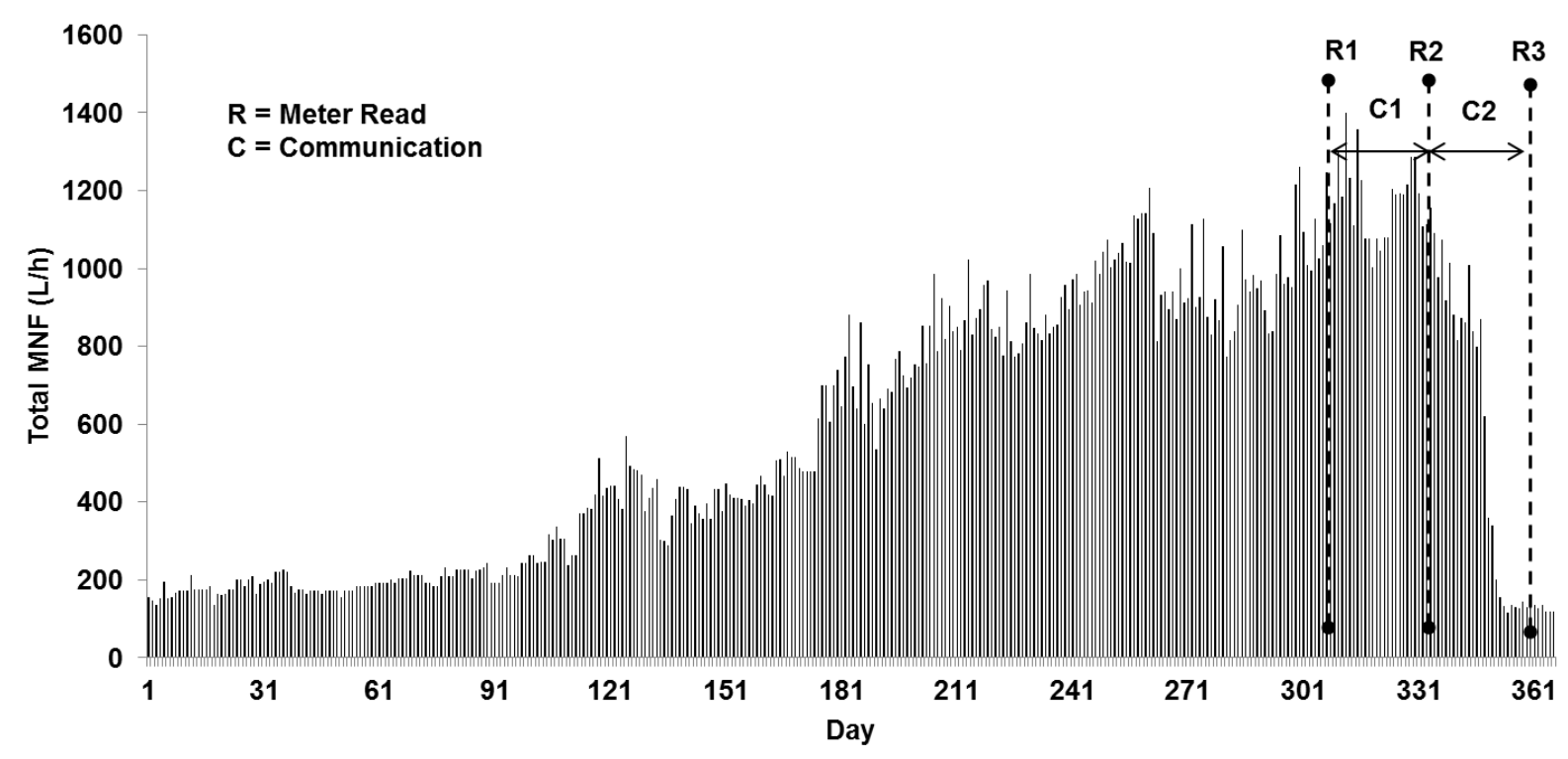

(a) Change in MNF over study period (pre- and post- intervention) 


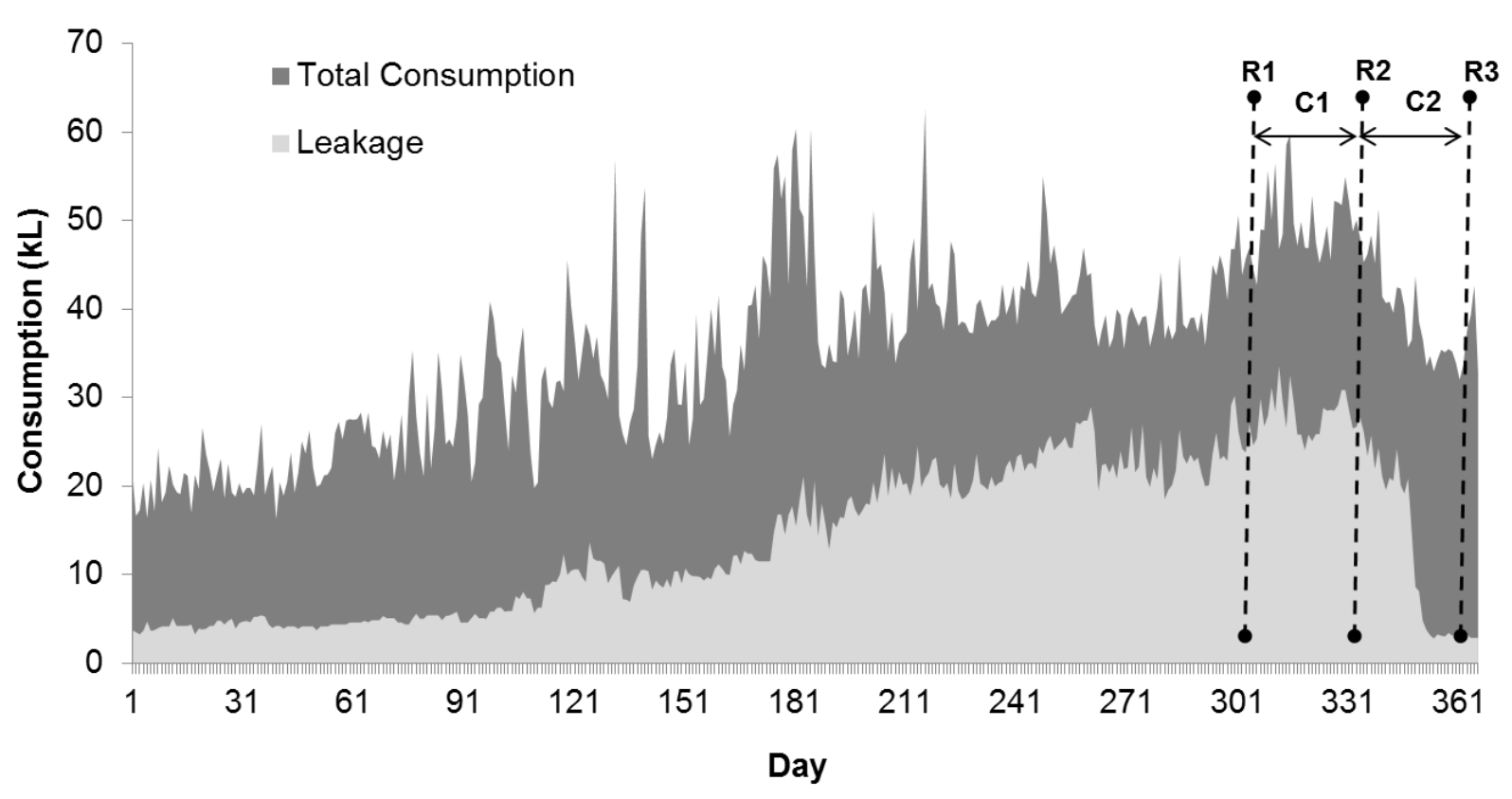

(b) Total and leakage consumption over study period (pre- and post- intervention)

Figure 3. Communication interventions affecting MNF for Group B

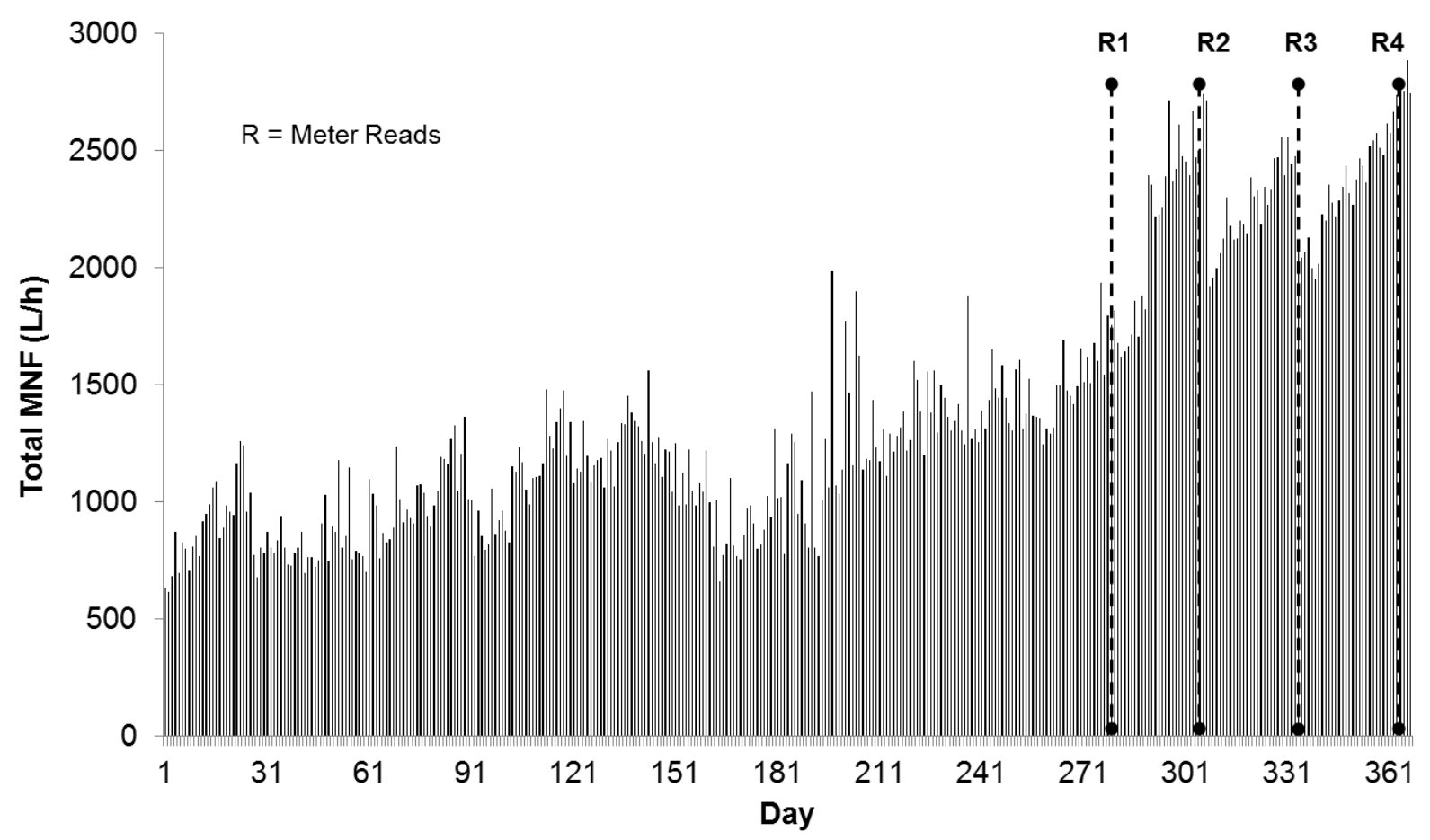

(a) Change in MNF over study period (pre- and post- intervention) 


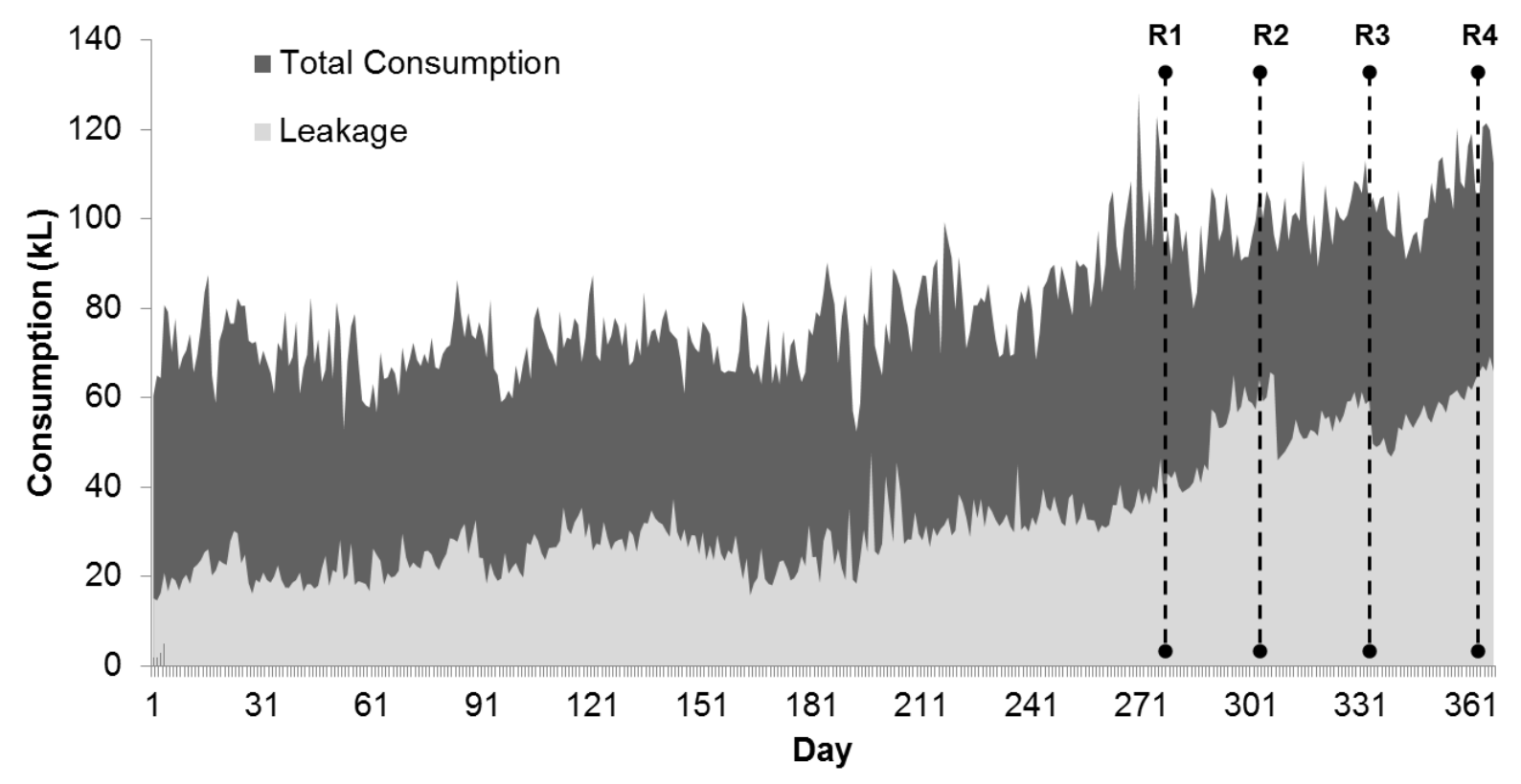

(b) Total and leakage consumption over study period (pre- and post- intervention)

Figure 4. Control group meter reads (Group C)

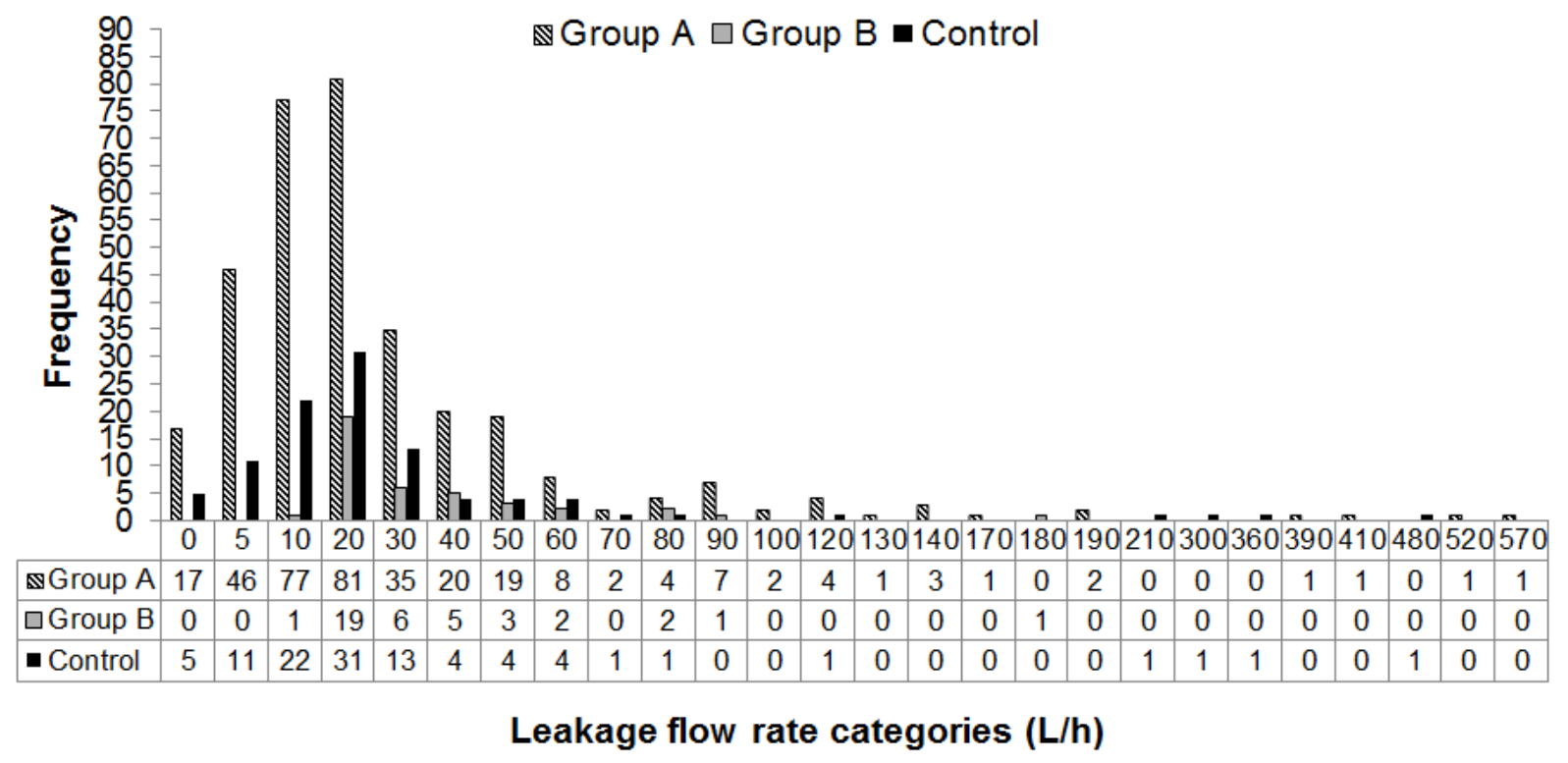

Figure 5. Frequency histogram of leak flow rate categories 


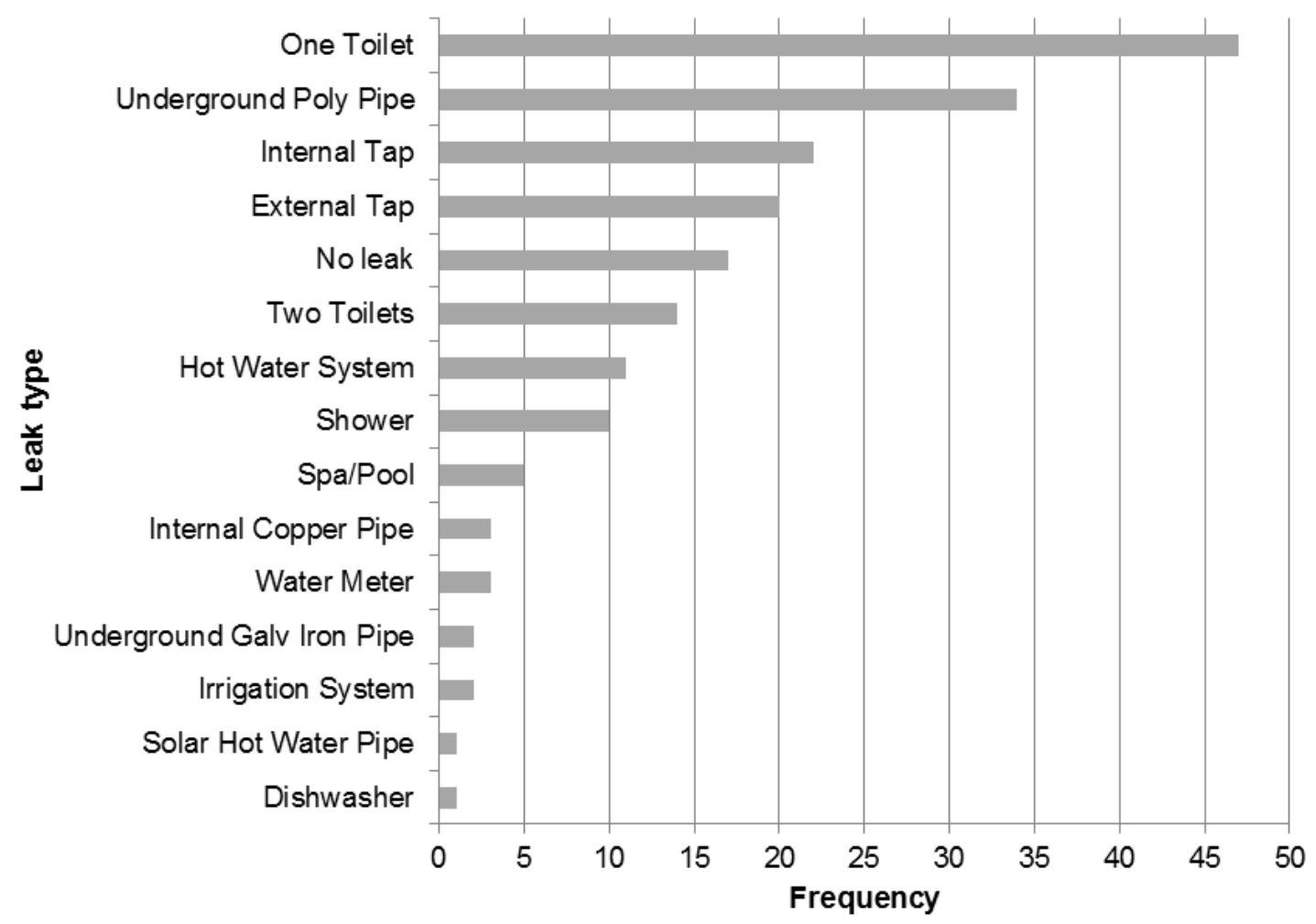

Figure 6. Frequency histogram of determined leak types

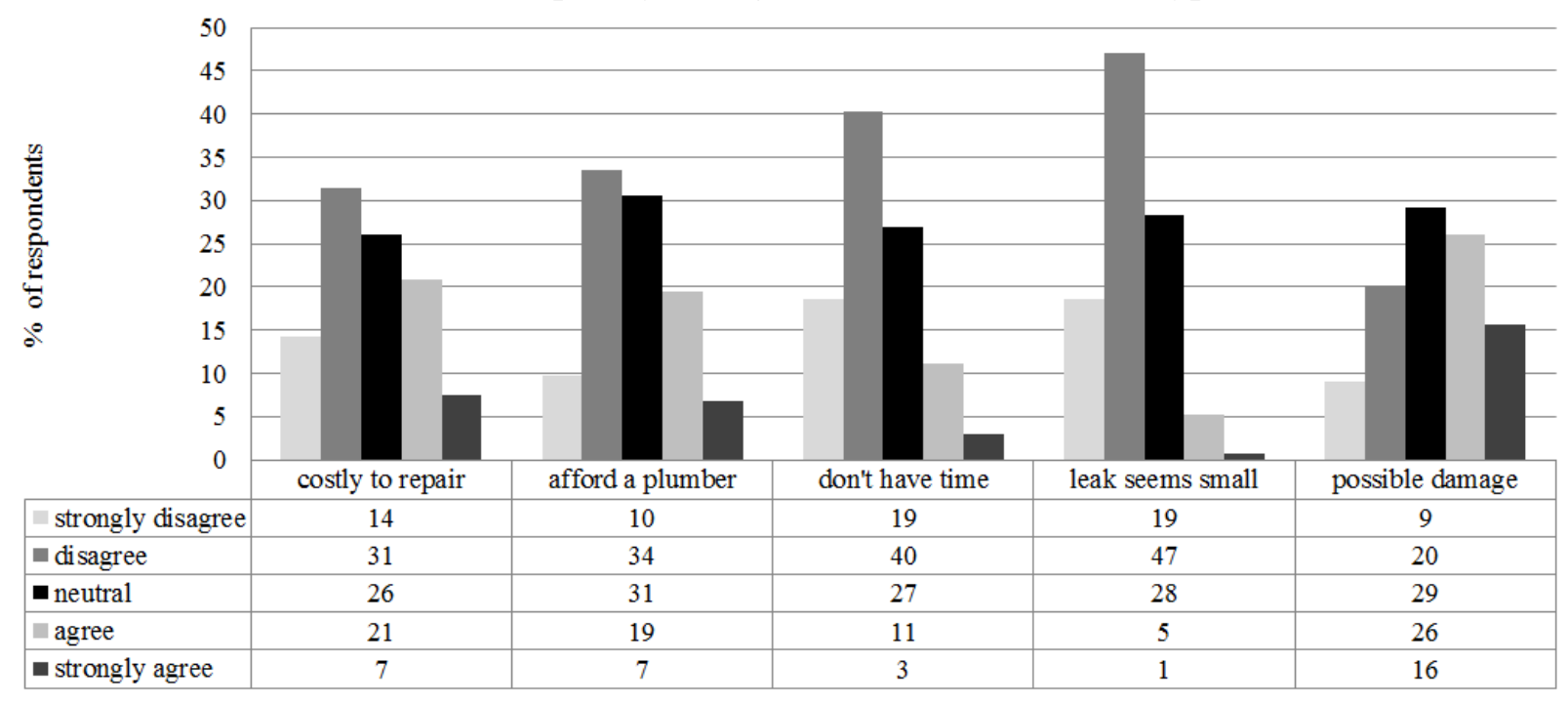

(a) Concerns about leak 


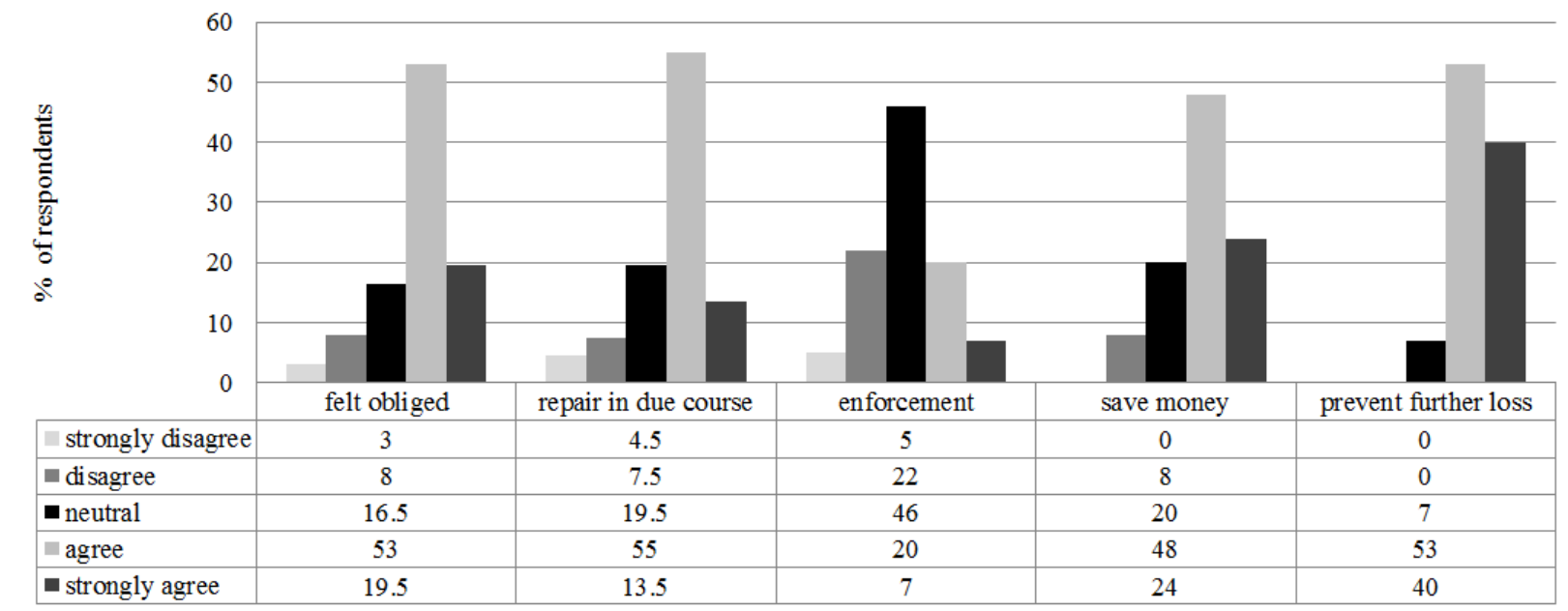

(b) Motivation to repair leak

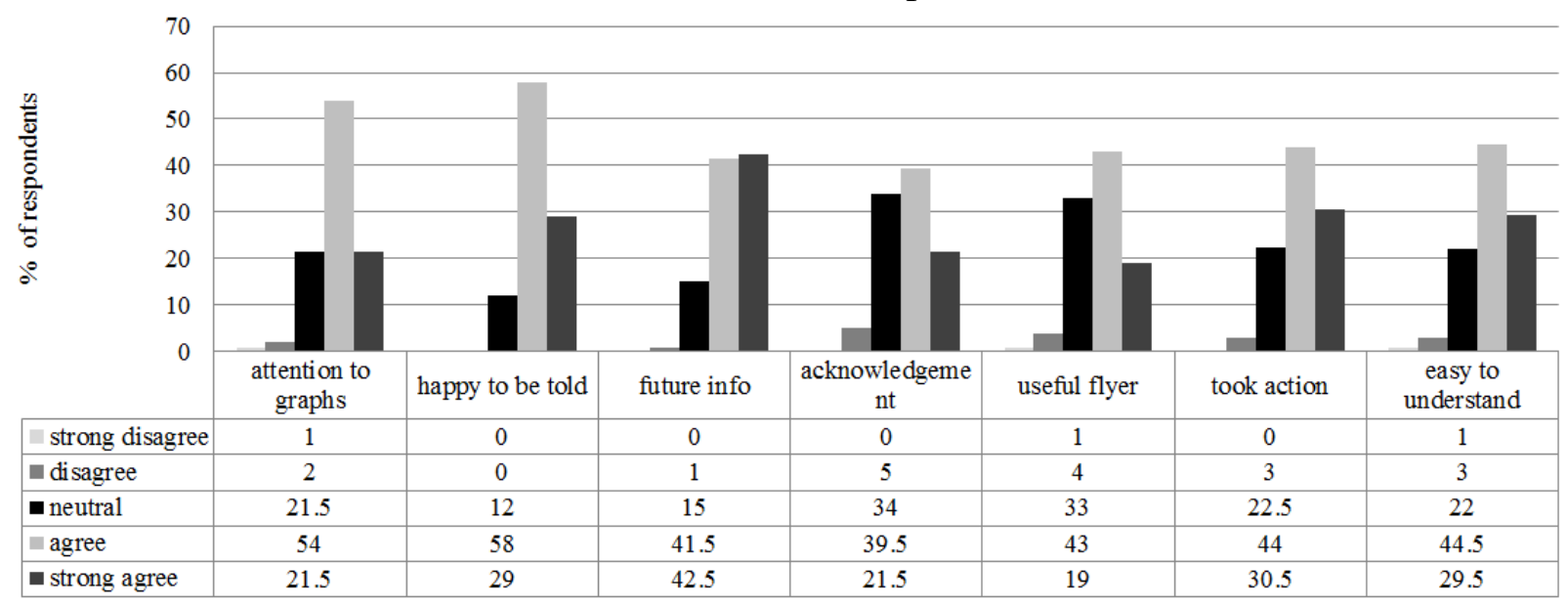

(c) Quality of information provided

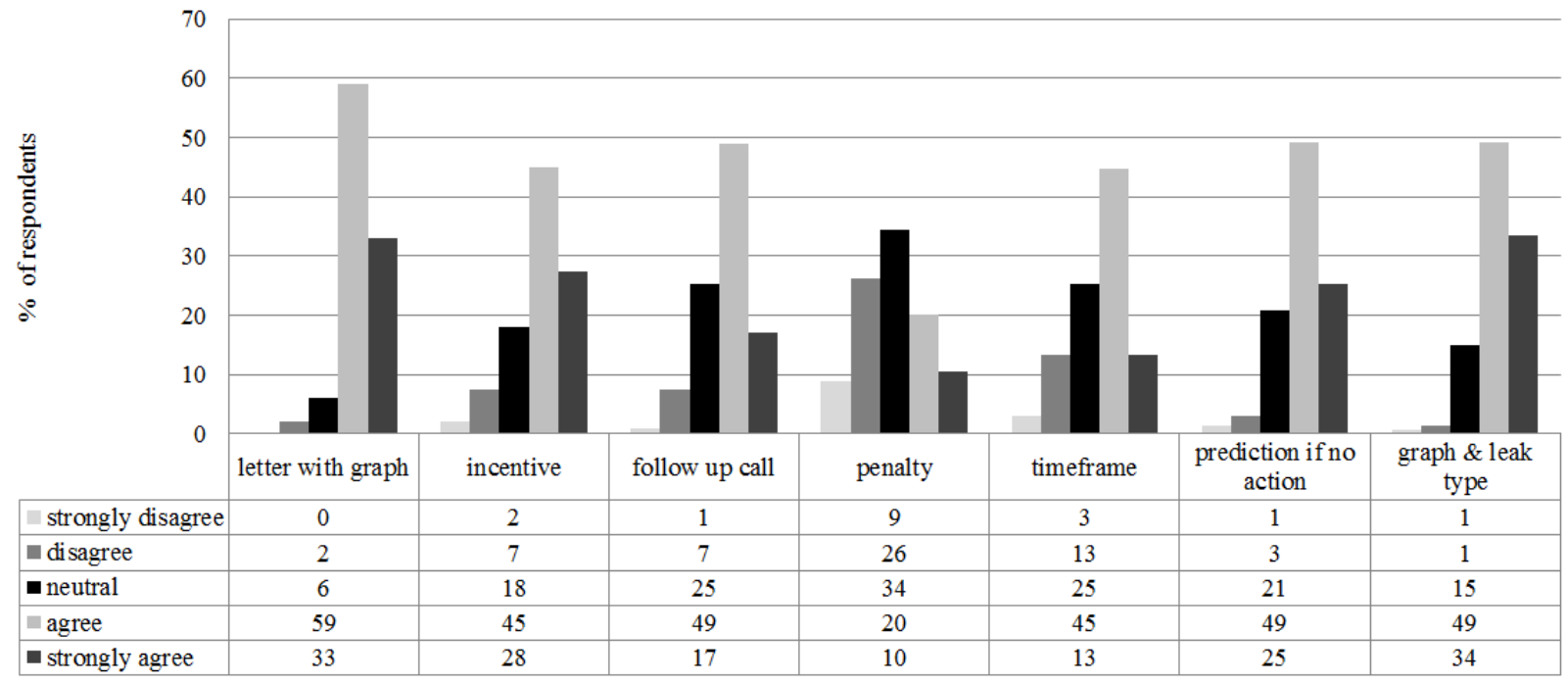

(d) Recommendations on future information provision 
Figure 7. Household perceptions of post meter leakage and applied communication strategy

\begin{tabular}{|c|c|c|c|c|}
\hline \multirow{9}{*}{$\begin{array}{l}\text { Measured } \\
\text { Minimum } \\
\text { Night Flow }\end{array}$} & \multirow{3}{*}{\multicolumn{2}{|c|}{$\begin{array}{l}\text { Utility Night Leakage on } \\
\text { mains and service } \\
\text { connections to } \\
\text { customer meters }\end{array}$}} & \multicolumn{2}{|c|}{ Assessed Unreported Leakage } \\
\hline & & & \multirow{2}{*}{$\begin{array}{l}\text { Background Leakage on } \\
\text { mains and service } \\
\text { connection up to } \\
\text { customer meters }\end{array}$} & On Mains \\
\hline & & & & On Service Connections \\
\hline & \multirow{6}{*}{$\begin{array}{c}\text { Customer } \\
\text { Night } \\
\text { Consumption }\end{array}$} & \multirow{3}{*}{$\begin{array}{l}\text { Customer } \\
\text { Night } \\
\text { Leakage }\end{array}$} & Background Leakage & \multirow{2}{*}{$\begin{array}{l}\text { Other leakage after the } \\
\text { meter }\end{array}$} \\
\hline & & & \multirow{2}{*}{$\begin{array}{c}\text { Leakage on service } \\
\text { connection and within } \\
\text { properties after customer } \\
\text { meters }\end{array}$} & \\
\hline & & & & On leaking toilet cisterns \\
\hline & & \multirow{3}{*}{$\begin{array}{l}\text { Customer } \\
\text { Night Use }\end{array}$} & Exceptional Night Use & $\begin{array}{c}\text { Residential and Non- } \\
\text { Residential }\end{array}$ \\
\hline & & & \multirow{2}{*}{ Assessed Night Use } & Non Residential \\
\hline & & & & Residential \\
\hline
\end{tabular}

Figure 8. Components of MNF (Adapted from Lambert 2010)

Tables:

Table 1. Hervey Bay Network System Performance 2007 - 2008 (WBWC, 2008)

\begin{tabular}{ll}
\hline Performance indicator & Value \\
\hline Infrastructure leakage index & 1.05 \\
Average pressure & $43.3 \mathrm{~m}$ water column \\
Real losses & $507 \mathrm{ML} / \mathrm{y}$ \\
& $1.39 \mathrm{ML} / \mathrm{d}$ \\
Unavoidable annual real losses & $485 \mathrm{ML} / \mathrm{y}$ \\
& $1.32 \mathrm{ML} / \mathrm{d}$ \\
No. of connections & 23,818 \\
Length of main & $750 \mathrm{~km}$ \\
\hline
\end{tabular}


Table 2. Communication interventions

\begin{tabular}{|c|c|c|}
\hline No. & Group A $(n=332)$ & Group B $(n=40)$ \\
\hline $1^{\mathrm{st}}$ & $\begin{array}{l}\text { Basic letter } \\
\text { Fact sheet }\end{array}$ & $\begin{array}{l}\text { Detailed letter including loss per hour, day and year } \\
1 \text { graph of consumption over } 24 \text { h period } \\
\text { Fact sheet }\end{array}$ \\
\hline $2^{\text {nd }}$ & $\begin{array}{l}\text { Detailed letter including loss per hour, day \& year } \\
\text { Graphs of consumption over two } 24 \text { h periods i.e. } \\
\text { week } 1 \text { then week } 4 \text { of monitoring } \\
\text { Fact sheet }\end{array}$ & $\begin{array}{l}\text { Letter stating customer still has leak } \\
\text { Graphs of consumption over two } 24 \text { h periods i.e. } \\
\text { week } 1 \text { then week } 4 \text { of monitoring } \\
\text { Rebate offer AUD } \$ 100 \text {, valid for } 21 \text { days }\end{array}$ \\
\hline $3^{\text {rd }}$ & $\begin{array}{l}\text { Letter stating customer still has leak } \\
\text { Graphs of consumption over two } 24 \text { h periods i.e. } \\
\text { week } 5 \text { then week } 8 \text { of monitoring } \\
\text { Rebate offer AUD } \$ 100 \text {, valid for } 30 \text { days }\end{array}$ & Thank you letter with graphs pre and post leak repair \\
\hline $4^{\text {th }}$ & Thank you letter with graphs pre and post leak repair & Scheme evaluation questionnaire \\
\hline $5^{\text {th }}$ & Scheme evaluation questionnaire & \\
\hline
\end{tabular}

Table 3. MNF values pre- and post- communication interventions

\begin{tabular}{|c|c|c|c|c|}
\hline \multirow[t]{2}{*}{ Intervention stage } & \multirow{2}{*}{$\begin{array}{c}\text { Sample average MNF } \\
\mathrm{L} / \mathrm{h}\end{array}$} & \multicolumn{2}{|c|}{ Cumulative $\Delta \mathrm{MNF}^{\mathrm{a}}$} & \multirow{2}{*}{$\begin{array}{c}\text { Household average MNF* } \\
\text { L/h }\end{array}$} \\
\hline & & $\mathrm{L} / \mathrm{h}$ & $\%$ & \\
\hline \multicolumn{5}{|c|}{ Group A $(n=332)$ interventions } \\
\hline Pre & 4,009 & 0 & 0.00 & 12.08 \\
\hline $1^{\mathrm{st}}$ & 2,644 & $-1,365$ & -34.05 & 7.96 \\
\hline $2^{\text {nd }}$ & 1,169 & -2.840 & -70.84 & 3.52 \\
\hline $3^{\text {rd }}$ (End) & 494 & -3.515 & -87.68 & 1.49 \\
\hline \multicolumn{5}{|c|}{ Group B $(n=40)$ interventions } \\
\hline Pre & 1,356 & 0 & 0.00 & 33.90 \\
\hline $1^{\text {st }}$ & 840 & -516 & -39.82 & 21.00 \\
\hline $2^{\text {nd }}$ (End) & 120 & $-1,236$ & -91.15 & 3.00 \\
\hline \multicolumn{5}{|c|}{ Group C $(n=100)$ Meter reads only } \\
\hline $1^{\text {st }}$ & 1,839 & 0 & 0.00 & 18.39 \\
\hline $2^{\text {nd }}$ & 2,506 & +667 & +36.27 & 25.06 \\
\hline $3^{\text {rd }}$ & 2,073 & +234 & +12.72 & 20.73 \\
\hline $4^{\text {th }}$ (End) & 2,799 & +960 & +52.20 & 27.99 \\
\hline
\end{tabular}

${ }^{\mathrm{a}}$ Cumulative change in MNF compared against baseline pre-intervention value or $1^{\text {st }}$ read in the case of control group. 